Session Number 2630

\title{
An Integrated Approach to Developing Professional and Technical Skills in Engineering Undergraduates
}

\author{
Thomas A. Litzinger, Professor \\ Mechanical Engineering, Penn State, University Park, PA 16802
}

\begin{abstract}
The general consensus in industry, government, and academia is that engineers will need more highly developed professional skills to succeed in the new millenium. Of the ABET EC2000 eleven basic outcomes, six relate to professional skills such as communication, teamwork, and understanding broader issues related to engineering. Thus, engineering programs must find ways to more effectively develop students' professional skills, without sacrificing the development of their technical skills. This paper describes one approach to achieving the simultaneous development of professional and technical skills, which requires students to practice these skills in an integrated fashion within a realistic context. This approach was implemented in a senior elective on internal combustion engines, which provided the technical focus for the course. The core of the approach is problem-based learning; however, critical to the approach are explicit objectives related to oral and written communication, team skills, consideration of engineers' roles in society and the effects of society on engineering, and application of engineering fundamentals in design and computer modeling. The paper describes the course objectives, the course structure, and the specific tasks that students were asked to undertake in teams. These relationship of the course structure and the ABET outcomes are also discussed. For each task, the quality of the students' work is discussed along with selected comments from students on how they perceived the tasks. Detailed assessment was performed throughout the course; its structure and some highlights of the results are presented.

Introduction

Industry, academia, professional societies, and the federal government have been calling for enhancement of engineering education to properly prepare students for success in the highly competitive, global marketplace. The NSF report, Shaping the Future, ${ }^{1}$ points out that "too many graduates go out into the workplace ill-prepared to solve real problems in a cooperative way, lacking the skills and motivation to continue learning." The NRC report, Engineering
\end{abstract}


Education: Designing an Adaptive System, ${ }^{2}$ asks many questions about engineering education including:

"Does engineering education integrate the fundamentals well enough with design and experimentation?"

"Does the curriculum instill a sense of the social and business context and the rapidly changing, global nature of engineering today and in the future?"

The ABET EC2000 criteria emphasize the importance of technical and professional skills of engineering students through the outcomes common to all engineering programs; six of eleven of these relate to professional skills such as communication skills, team skills, and an understanding of the societal and ethical aspects of engineering.

One very difficult question facing engineering programs today is how to meet these high expectations without increasing credit hours or overburdening students with unrealistic workloads. Individual faculty as well must come to grips with their personal approaches to meeting these expectations. What is described in this paper is one approach to achieving the simultaneous development of the professional and technical skills by allowing students to practice these skills in an integrated fashion within a realistic context. The core of the approach is problem-based learning; however, critical to the approach are explicit objectives related to oral and written communication, team skills, consideration of engineers' roles in society and the effects of society on engineering, and application of engineering fundamentals in design and in computer modeling. The approach described represents one model for helping students develop more fully as engineers during their studies and can be applied to any engineering course, at an appropriate level of sophistication. In fact, this model has been applied to some extent in many first-year engineering design courses, e.g., references 3 and 4, and even in pre-engineering courses for high school students. ${ }^{5}$

\section{Description of Course and Teaching/Learning Methods}

The highly integrated course described here developed in an evolutionary fashion over several years. Through its various phases, this course included some of the elements of the integrated approach including problem-based learning, technical writing, and "mindtools;", however, they were not all integrated into the approach described here until Spring semester of 1999. In the design of the course, the various assignments were specifically designed to draw upon prior knowledge and to have students use it along with their newly acquired knowledge in working on meaningful tasks, following Novak's recommendations for promoting meaningful learning. ${ }^{7}$ In this case, problem-based learning was used to provide the meaningful tasks. It was also hoped that the problem-based learning would motivate the students to learn meaningfully, and the tasks were designed so that rote learning would not be sufficient to accomplish them. Teams were an integral part of the approach used not only to provide an opportunity to allow students to develop their team skills, but also to provide a vehicle for discussion and "constructing" of knowledge, consistent with the constructivist approach to learning. ${ }^{8}$

Key skills and prior knowledge incorporated into the course included elements of thermodynamics, fluid mechanics, heat transfer, electrical engineering, mechanical design, instrumentation, technical writing, and oral communication. The original course plan included the use of statistics in the analysis of experimental results; however, insufficient time was 
available to complete this aspect of the course. A substantial portion of the course was also aimed at helping students understand how engines operate with an emphasis on thermal-fluids aspects including combustion. In addition, engineering ethics and interactions of engineering and society were incorporated, so some class time was used to discuss related topics including "justice" and the complexities of cost-benefit analyses.

The learning objectives presented to the students at the beginning of the course were:

- Students will demonstrate a basic understanding of engine function, performance, emissions, and design constraints through their design projects reports and presentations.

- Students will demonstrate their ability to use the thermal sciences in the analysis and preliminary design of engine systems by creating a thermodynamic model of a spark ignition engine and through their design reports.

- Students will demonstrate their understanding of the interactions of technology and society through reflective essays and their reports on the ethical and societal impact of the regulation of small engine emissions.

- Students will demonstrate effective team skills though successful completion of multiple team-based tasks and during in-class project sessions.

- Students will demonstrate effective written and oral communication skills through their reports, papers, and presentations.

The specific problem presented to the class came from a writer for a gardening magazine who was interested in having lawn mower engines tested for emissions and fuel economy. Given the changing state-of-the-art in these engines that is being driven by emissions regulations, the problem presented a perfect opportunity to fully integrate technical and professionals skills in a single course. In addition, appropriate dynamometer and test equipment were not available so that the students had the opportunity to design a complete test set-up from scratch. A very limited budget was available for implementation of their designs, so realistic cost constraints were imposed.

In order to make the project manageable for the students, it was divided into five parts:

1. Design of an engine dynamometer specifically for the testing of lawn mowers.

2. Design of an experimental set-up to conduct the test including measurement of fuel and air flow and exhaust emissions, which required some method to prevent condensation in the engine exhaust.

3. Consideration of the ethical aspects and societal impact of the proposed EPA regulations for small off-road engines.

4. Formulation and solution of a numerical model of thermodynamic cycle of a spark ignition engine that could model effects of compression ratio, spark timing, combustion duration, and power level.

5. Writing a final paper that summarized the motivation for the study, the experimental procedure, the test results, and major conclusions in a manner appropriate for publication in the gardening magazine.

For each phase of the project, the students were given a brief description of the required work as well as explicit scoring criteria. Additional aspects of the work in the course were technical briefings that were incorporated into the first four phases of the project. All teams were required 
to come to class prepared to present, and four teams were selected to give five minute presentations. Following each presentation, the class engaged in discussion with the presenting team. In order to promote high quality interactions in this discussion, the number of meaningful questions asked by each team was noted and became part of their grade. In addition, written reports were required for each phase of the project. An additional writing project used prior to class discussion of engineering ethics required each student to write a personal definition of engineering and to describe engineers' roles in society, without the aid of references or consultation with others. One other piece of writing was required of the students as part of their final. This assignment asked them to reflect back over the course to understand what aspects of the course most helped them develop as engineers from both a technical and professional perspective.

An overall goal of the design of the course was to have some aspect of it that would address each of the eleven EC2000 outcomes. In the end, the course explicitly addressed ten of the ABET outcomes, and implicitly addressed the remaining one on lifelong learning. In carrying out their work on the project the students had to be highly self-directed in identifying, acquiring and evaluating a wide range of information needed for their projects. All of these skills are critical to effective lifelong learning. ${ }^{9}$. The relationship of the phases of the project and the EC2000 outcomes are presented in Table 1.

The class had 42 students, 39 of whom were mechanical engineering seniors. Three graduate students were also in the class, two Masters degree students from the Fuel Science Program and one $\mathrm{Ph}$. D. student from electrical engineering. To gauge the level of students' prior knowledge of engines, they were asked to create a concept map ${ }^{7}$ of the operation of an engine using twenty specific terms. The students' knowledge of engines ranged from a great deal, for a returning adult student who had been an engine technician, to essentially none at all. The students were placed into ten teams based upon a survey that asked for their self-evaluation of a number of skills including engineering analysis, experimentation, writing, oral communication, and library skills. Other factors that were considered in forming the teams included prior knowledge of engines, common times for team meetings, and students' indication of others that they would like to team with. During the class that the teams were formed, each team was required to formulate a team contract with specific statements on how they would run and how they would deal with "slackers." Each group was required to type up their contract, sign it, and turn a copy in with their first design report.

\section{Design of Dynamometer}

The request from the writer for the gardening magazine was discussed in class to give the students an understanding of the context of the project. Constraints on time and funds were also discussed prior to the distribution of the first part of the project, which required the students to design a dynamometer. The specific design requirements were for a dynamometer capable of simulating two different power/speed conditions that roughly corresponded to mowing dry and wet grass. Additional constraints were that the dynamometer should require minimal modifications to the mowers and that they must be safe in the event of a failure. The final constraint was to limit cost to approximately $\$ 100$. The teams had three weeks for this part of the project. 
Table 1. Matching of various aspects of the project to ABET outcomes

\begin{tabular}{|c|c|c|c|c|c|}
\hline & $\begin{array}{l}\text { Design } \\
\text { dyno }\end{array}$ & $\begin{array}{l}\text { Design } \\
\text { instrumen- } \\
\text { tation }\end{array}$ & $\begin{array}{l}\text { Societal \& } \\
\text { ethical analysis } \\
\text { of EPA } \\
\text { regulations }\end{array}$ & $\begin{array}{c}\text { Formulate } \\
\& \text { solve } \\
\text { model }\end{array}$ & $\begin{array}{l}\text { Write } \\
\text { article for } \\
\text { gardening } \\
\text { magazine }\end{array}$ \\
\hline $\begin{array}{l}\text { a) Apply knowledge of } \\
\text { math, science and } \\
\text { engineering }\end{array}$ & $\mathrm{X}$ & $\mathrm{X}$ & & $\mathrm{X}$ & \\
\hline $\begin{array}{l}\text { b) Design and conduct } \\
\text { experiments }\end{array}$ & & $\mathrm{X}$ & & & $\mathrm{X}$ \\
\hline $\begin{array}{l}\text { c) Design a system, } \\
\text { component or process }\end{array}$ & $\mathrm{X}$ & & & & \\
\hline $\begin{array}{l}\text { d) Function on multi- } \\
\text { disciplinary teams }\end{array}$ & $\mathrm{X}$ & $\mathrm{X}$ & $\mathrm{X}$ & $\mathrm{X}$ & $X$ \\
\hline $\begin{array}{l}\text { e) Identify, formulate, and } \\
\text { solve engineering } \\
\text { problems }\end{array}$ & $X$ & $\mathrm{X}$ & & $\mathrm{X}$ & \\
\hline $\begin{array}{l}\text { f) Understand professional } \\
\text { and ethical responsibility }\end{array}$ & & & $\mathrm{X}$ & & \\
\hline $\begin{array}{l}\text { g) Communicate } \\
\text { effectively }\end{array}$ & $\mathrm{X}$ & $\mathrm{X}$ & $\mathrm{X}$ & $\mathrm{X}$ & $\mathrm{X}$ \\
\hline $\begin{array}{l}\text { h) Understand impact of } \\
\text { engineering solutions in } \\
\text { global context }\end{array}$ & & & $\mathrm{X}$ & & \\
\hline i) Lifelong learning & $\mathrm{X}$ & $\mathrm{X}$ & $X$ & & \\
\hline $\begin{array}{l}\text { j) Knowledge of } \\
\text { contemporary issues }\end{array}$ & & & $\mathrm{X}$ & & \\
\hline $\begin{array}{l}\text { k) Use techniques, skills, } \\
\text { and modern engineering } \\
\text { tools }\end{array}$ & $\mathrm{X}$ & $\mathrm{X}$ & & $\mathrm{X}$ & \\
\hline
\end{tabular}

Students were required to produce a report that discussed their design process including alternatives considered and rejected, an explanation of the operating principle of their design, and engineering calculations that supported their design choices. The requirement to back-up their design choices with engineering estimates was included specifically to force students to return to their fundamental knowledge and apply it in their design process. In addition, drawings were required that were sufficiently detailed, including tolerances, that a technician could fabricate their designs.

Overall the designs received from the students were quite good; the scores for all groups, but one, were 83 and above. In general the teams considered three or more options before making their final selections. In the end, approximately half of the teams used a simple friction brake 
design, which they had seen in a previous class. Other designs included a hydraulic pump with a gate valve to control load, an electric dynamometer with resistors for load control and energy dissipation, and a fan-brake. Many of these teams showed good creativity in their designs, especially when they sought to keep costs down. A common problem with the friction brake design was heat generation, which led the teams to do estimates of heat generation and heat transfer rates. Some groups had difficulty making such estimates and using their engineering knowledge in the design process; this was particularly true for groups with lots of engine experience. Initially their designs were based entirely on intuitive insights, but with some coaching they began to use their analytical skills as well.

Four teams that had chosen different designs, friction, hydraulic, fan, and electric, were asked to present to the class. Three of four teams gave good presentations, while the fourth suffered from an obvious lack of preparation. (The fourth team turned out to need assistance with team skills, which resulted in successively better performance as they worked on later phases of the project.) Each team was evaluated by the instructor and the class on three criteria: quality of visuals used, clarity of presentation, and ability to handle questions. The assessments of the instructor and the students correlated reasonably well. In all cases, the evaluation of the performance in the question and answer period was better than in the formal presentation. On average, each group received six questions from the class, and discussion had to be cut-off due to time limitations.

Feedback was solicited from the class following the completion of the dynamometer design. The most commonly noted item for improvement in future parts of the project was to have an actual mower available for measurement. This problem arose because the support from the gardening magazine failed to materialize due to a corporate restructuring that happened just before the semester started. As a result, no mowers were donated to the class, so the students had no hardware to look at when they were doing their designs. This situation was discussed in class as it evolved so that the students gained a sense of the dynamic nature of the modern workplace. Several students responded negatively to the fact that all teams had to come prepared to present and that only three were chosen. They viewed this practice as an inefficient use of their time and resources. This aspect of the course was eventually changed, after similar comments arose following Part 2 of the project. The third major comment related to increasing the clarity of what was expected in the reports; as a result the students were given the complete scoring sheet used by the instructor with each subsequent part of the project. For most groups, the total time spent on the project ranged from 10 to 15 hours. However, one group spent more than 30 hours, and commented that the next phase of the project needed to be narrower in scope.

\section{Design of Experimental Set-up}

Part 2 of the project, design of the experimental set-up, was structured in a similar way to the dynamometer design. The requirements included design of instrumentation for measuring fuel consumption and intake air flow with supporting calculations for selecting the appropriate range or sensitivity. In addition, a sampling system had to be designed to withdraw a sample from the engine exhaust with some form of conditioning to eliminate condensation of hydrocarbons or water in the exhaust. Analyzers for measurement of the mole fractions of $\mathrm{CO}, \mathrm{CO}_{2}, \mathrm{NO}_{\mathrm{x}}$ and unburned hydrocarbons were available in the instructor's research labs. The students were required to consider how to convert the mole fractions into usual engineering units of $\mathrm{gm} / \mathrm{kW}$-hr as well as how to present the emissions in a form that would be easily understood by readers of 
the gardening magazine. Once again safety issues had to be considered as part of the design, and cost was to be constrained as much as possible. The design report was to include equipment specifications, rationale for choices of equipment, overall experimental layout, a cost estimate and a description of methods to present the data in typical units and for the gardening magazine. The teams had three weeks to complete this phase of their work.

The performance on the designs and the quality of the reports were again quite good, with all but one team receiving scores of 88 or higher. The designs for measurement of the amount of fuel used were mostly based upon the volume of fuel consumed, although one group did propose a gravimetric measurement. The air flow rate measurements proposed were a critical flow orifice or a rotameter. The greatest diversity of ideas came in the design of methods to prevent condensation in the exhaust. A number of teams set up systems to dilute the exhaust based upon discussion in class of the design of such systems. However, other methods were proposed including insulating the exhaust system, heating the exhaust system or using a dessicant to dry the exhaust. The presentations were better than those for the first part of the project; whether this represents an improvement resulting from watching the first round of presentations or was simply due to the fact that different teams presented is not clear. Again, all four teams handled questions well; each received an average of six questions.

The general comments and suggestions included a few that indicated that the students did not see this part of the project as sufficiently relevant to engines. One student noted that "the part we just completed would have been interesting to a chemical engineer." For the most part, however, few students made suggestions for improvement, and most seemed to be satisfied with this part of the project. At this point, the issue of what lawn mowers would be tested still had not been resolved, which was noted as a source of difficulty in the design by some of the students.

\section{Construction of the Experimental Facility}

Shortly before the completion of Part 2, it became clear that the gardening magazine would not be providing any support for the project nor would it be able to provide lawn mowers. This situation led to a need to quickly rearrange some of the expectations for the testing aspects of the project. In the end, resources were provided by the Mechanical Engineering Department to allow the purchase of a Honda generator. The generator provided the dynamometer needed for control of the engine and the engine itself was state-of-the-art. In addition, Nelson, Inc. donated a small catalytic converter for use in testing. Since one of the options being considered by EPA would require the use of catalytic converters, the test plan was rearranged to include testing of the engine with and without the catalytic converter.

Based upon the various designs of the test set-up provided by the students, the instructor put together an overall design using critical flow orifices for air flow, gravimetric measurement of the fuel flow, and a dilution scheme to eliminate condensation in the exhaust. A graduate teaching assistant assembled the test rig and ran shake-down tests, prior to its use by the students.

\section{Engineering and Society/Engineering Ethics}

Prior to discussion of the areas of engineering ethics and the interactions of engineering and society, the students were asked to write individual essays which explained their personal 
definitions of engineering and also their personal views on the roles and responsibilities of engineers in society. These essays were to be written without reference to any materials and without discussion with others. The students were given one week to write the essay, and it was due on the day that discussion of these topics began in class.

The sophistication and clarity of the students' definitions of engineering were pleasantly surprising. This assignment elicited some interesting responses from several students. One questioned why no one asked him to write such an essay prior to his senior year, and he suggested that this type of essay be required of students prior to the selection of a major. Another was grateful for the assignment because a family picnic was coming up, and now he would be able to explain what it is that engineers do. With respect to the goals of engineering, and the roles and responsibilities of engineers in society, nearly all of the students expressed their belief that the roles of engineers are to create products and processes that would improve the lives of individuals in society. One student suggested that engineers should take something like a Hippocratic oath. This statement led to a discussion of the Order of the Engineer and also statements on professional practice from several engineering societies.

Following discussion of the essays, several classes were spent discussing interactions of engineers and society. Topics discussed included the different ways in which the interaction occurs, the different types of justice as tools for considering effects of technology on society, and the difficulties inherent in cost-benefit analyses. One particularly provocative issue discussed was the fact that typical costing methodology places on lower value on the life of a woman than on a man, based upon estimates of lost wages!

The students then received Part 3 of the project that asked them to consider four options for regulations of emissions from lawn mowers:

i) no regulations,

ii) limits attainable by modification of engine design,

iii) limits attainable with use of catalytic converters, and

iv) zero emission limits, requiring use of electric mowers.

The assignment asked the students to describe the costs and benefits of each of these four options, considering the point of view of justice, i.e., distributive, intergenerational, and ecological. They were asked to discuss the kinds of information that they would need to make a decision on which option to use and to describe the decision making process. They were not asked to gather the data and make a decision, as that would have been well beyond the scope of the course.

As structured, the assignment caused some difficulty for the students, because the suggested format was quite repetitive in that each option had to be considered for cost/benefits and justice. However, they still succeeded in doing a lot of good thinking and learning. Some of the costs that they discussed were costs to the consumer in terms of money, time and freedom of choice, costs to the manufacturers, possible loss of jobs, and even destruction of companies. Benefits included improved health in society as a whole, reduced ecological impact, and the possible creation of new jobs. Some of the weaker portions of the papers related to the process of how to reach a decision. Overall, however, the class did well, receiving grades of 88 and above. The inclass presentations and discussions were again rated good to very good, but there were far fewer 
questions than on the design assignments, with each group receiving only two or three questions. It is not clear why this was the case; it could have been the material itself or the fact that the students were beginning to wear out as the semester progressed.

One question on the post-assignment survey asked whether ethics and the related part of the project should be kept in the class in the future. The students were overwhelmingly supportive of keeping the topic and the project, with some noting that this topic is rarely if ever addressed in other classes. However, a few students were not supportive; a representative comment from this group was

"Drop it! Even though this stuff is important, it is out of the scope of the class! I am not learning very much about I.C. engines themselves in this class."

\section{Formulation and Numerical Solution of Thermodynamic Engine Model}

The fourth part of the assignment required the students to draw upon their knowledge of engines, slider-cranks, and thermodynamics to construct a model of an engine. Formulating, constructing, and experimenting with such models engages students in critical thinking about the engineering principles involved as well as the device under study. ${ }^{8}$ The results from the model were to be compared to those obtained from a commercial test rig with a small side-valve engine that was available in a thermodynamics lab. The students were asked to use the model to find the optimal timing for maximum torque, simulating the process of optimizing spark timing in a real engine. They were also required to use the model to investigate the expected changes that would occur if the engine were converted to an overhead valve configuration, like that used in the engine on the Honda generator. As part of an in-class discussion related to the model, the impact of the simplifying approximations was highlighted, and the students were asked to discuss what the impact of their approximations on the ability of their model to predict the experimental results.

This modeling has been used in the course for several years and always causes significant difficulty for the students. In most cases, it is the first time that they are asked to formulate a model of a physical device from scratch, even a relatively simple one. From the outset they have difficulties relating their thermodynamic knowledge of the First Law, the ideal gas law and the definition of work to the problem. Typically, they cannot rework the governing equations into a form that can be solved numerically. Then they have difficulty putting these equations into a spreadsheet or MATLAB. Additional difficulties arise when they try to use their knowledge of engines to make assumptions of combustion parameters, and to relate the change of engine design to the combustion parameters. In the end, most of the teams overcame these hurdles, but only six of ten groups had models that captured the "physics" correctly and that worked numerically. All of the group, however, did well in discussing the impact of their approximations on the model accuracy and the associated "physics" that were left out as a result.

No survey was distributed after this part of the project; however, it was discussed with the students several times in class and also during office hours. The teams that did succeed in building the model were very pleased with their accomplishment, and several of the teams were really engaged by the process. However, most of the students clearly had great difficulty with it and were eventually frustrated with the experience. Not only did they have trouble formulating the model, but many had difficulty trouble shooting their programs. The main issue was that a 
number of the groups used a spreadsheet to implement their model, so that their equations were a mishmash of dollar signs, letters and numbers, rather than variable names. It is the one part of the course that appears to need major efforts to improve it. Interestingly, however, only one student identified the modeling as the part of the course "liked the least" on the standard university evaluations of the course at the end of the semester.

Final Paper for Gardening Magazine

The final part of the project required the students to reduce data taken with and without the use of the catalytic converter to obtain emissions, fuel economy, and volumetric efficiency. Some of the data was taken by the groups themselves, and some was provided to them from testing done by the graduate teaching assistant. Taking the data was an optional part of the project because it came late in the semester; only four of the ten teams chose to take their own data. A summary of all data was provided to each team for their analysis.

Each team had to write a paper for the gardening magazine that included the following elements:

- Motivation for the study of engine fuel economy and emissions, including why tests were done with and without the catalytic converter

- Summary of the measurements that were made to obtain fuel consumption and emissions,

- Explanation of how a catalytic converter reduces $\mathrm{HC}, \mathrm{CO}$, and $\mathrm{NO}_{\mathrm{x}}$ emissions and what effect it might have on fuel economy,

- Summary of the test results for fuel economy and emissions with and without the catalytic converter

- Major conclusions

Because multiple groups took data and due to difficulties with getting the catalytic converter to work as expected, the opportunity arose to discuss issues of reliability of experimental data. Also the need to run enough tests to establish statistical confidence was discussed. However, due to lack of data and time, no statistical analysis was performed. The difficulties and the discussion of them did give the students an opportunity to understand the challenges of doing experimental work.

One of the evaluation criteria for their papers was the extent to which the report was appropriate for the audience of the gardening magazine. This proved to be the most challenging aspect of the writing for most of the teams. They tended to use engineering or scientific terms such as mole fraction or specific fuel consumption without explanation or they included complex chemical reactions. However, several teams did express the emissions in more meaningful units than $\mathrm{g} / \mathrm{kW}$-hr, such as total $\mathrm{kg} / \mathrm{year}$, or they normalized them to the baseline to show reduction with the converter. In general, the technical discussion in the papers indicated that the students understood the basic operation of a catalytic converter, the effects of emissions on the human body and the environment, and the operation of small engines. Grades on the papers were 82 and above with most in the 90's. 
Summary of Assessment Results

After the first part of the project, the students were asked to give comments and suggestions on the course. Approximately $50 \%$ of the students made positive comments about the course at this point, and another $25 \%$ had no comment. Of those who had negative comments, most were concerned that the level of knowledge of engines expected in the projects was too high for students with little experience with engines. Several noted the conflict of the project with "learning" more about engines and engine hardware. One student was clearly struggling with the learning environment and wrote:

"Teach me!! That is why I took an introductory class on engines, because I need introduced."

Students who struggle in more self-directed learning situations are a special concern. Research has shown that their learning can be adversely affected when they are not given the support they need to participate in such learning opportunities. ${ }^{9}$ One student clearly did not engage during inclass active learning activities, and he may very well have been the one who wrote this comment. Over time, with support and a little prodding, he did become more engaged, but his reflective essay opened with the following quote:

"This has probably been the oddest structured class I've taken in my college career. I think though that it closely represented what a real job might be like."

So while he never became truly comfortable with the class, he did come to believe that it modeled the workplace in some respects.

As part of the surveys the students completed throughout the semester, they were asked to address specific issues related to educational objectives of the course such as the extent to which the project engaged prior knowledge, what was the most important or valuable learning that occurred, and how well the teams were working. In addition, students were required to write a reflective essay as part of their final in which they discussed what portions of the course they expected to be most valuable to them when they entered their engineering careers. The quantity of assessment data received was quite large, and it will only be summarized here. The major observations from these surveys and reflective essays were

1. Design of the dynamometer and instrumentation definitely engaged students prior knowledge of a number of technical areas as well as their professional skills of working on teams, time management, writing, and oral communication.

2. The paper on the impact of the emissions regulations on society awakened students to the complexity of the effects of technology changes on society as well as the difficulty of making such assessments quantitative.

3. The aspect of the course most commonly identified as valuable in the reflective essay was the intensive experience of working in a team to deliver five parts of a project during the semester. Nearly $75 \%$ of the class discussed teams in their essays.

4. There was a clear message from a number of students that they wanted more of the class to be dedicated to discussing engines, rather than things like testing and societal implications of technology. 


\section{Conclusion}

Based upon the feedback from the students and also their performance on the various parts of the project, the learning objectives of the course were successfully achieved. From the perspective of the instructor, this course was a definite success. The students made significant progress in developing their technical and professional skills and learned a lot about engines along the way. The one aspect of the course that needs additional attention is the modeling of the engine cycle. This portion of the course is always most difficult for the students conceptually. New approaches are being planned and will be implemented the next time the course is offered.

\section{REFERENCES}

1. National Science Foundation, Shaping the Future: New Expectations for Undergraduate Education in Science, Mathematics, Engineering, and Technology, Advisory to Committee to the National Science Foundation, Directorate for Education and Human Resources, 1996.

2. Engineering Education: Designing an Adaptive System, National Research Council, National Academy Press, Washington, DC, 1995

3. Smith, K., Mahler, M., Szafranski, J., and Werner, D., Problem-based Learning Freshmen Design Course, ASEE Annual Conference Proceedings, 1997.

4. Devon, Richard; Hager, Wayne; Sathianathan, D.; Saintive, D.; Nowe, M.; Lesenne, J., Alliance by design: international student design teams, ASEE Annual Conference Proceedings ,1998

5. McKenna, A. and Agogino, A., Integrating Design, Analysis, and Problem Solving in an Introduction to Engineering Curriculum for High School Students, ASEE Annual Conference Proceedings, 1998.

6. Jonassen, D., Computers as Mindtools for Schools: Engaging Critical Thinking, Second Edition, Merrill/Prentice Hall, New Jersey, 1999.

7. Novak, J., Learning, Creating, and Using Knowledge: Concept Maps as Facilitative Tools in Schools and Corporations, Lawrence Erlbaum Associates, Publishers, Mahwah, NJ, 1998.

8. Jonassen, D., Designing Constructivist Learning Environments, in Iinstructional Theories and Models, Second Edition, Lawrence Erlbaum Associates, Mahwah, NJ. 1998.

9. Candy, P., Self-Direction for Lifelong Learning, Jossey-Bass Publishers, San Francisco,CA, 1991.

\section{THOMAS A. LITZINGER}

Thomas A. Litzinger is currently Director of the Leonhard Center for the Enhancement of Engineering Education and a Professor of Mechanical Engineering at Penn State, where he has been on the faculty for 15 years. Prior to his appointment as Director of the Leonhard Center, he was ECSEL local principal investigator and the Coalition-PI for Student and Faculty Development. His work in engineering education involves curricular reform, teaching and learning innovations, faculty development, and assessment. He has received the Eisenhower Award for Distinguished Teaching at Penn State as well as the Premier and Outstanding Teaching Awards from the Penn State Engineering Society (PSES). He has also received an Outstanding Research Award from PSES and an NSF Young Investigator Award. Prior to joining Penn State, Dr. Litzinger had four years our industrial experience with General Electric in power systems; he received his Ph. D. from Princeton in 1986. 